\section{Are Negative Community Attitudes Toward Welfare Recipients Associated With Unemployment? Evidence From an Australian Cross-Sectional Sample and Longitudinal Cohort}

\author{
Timothy P. Schofield' and Peter Butterworth ${ }^{1,2}$
}

Social Psychological and Personality Science 2018, Vol. 9(5) 503-5I5 (C) The Author(s) 2017 Article reuse guidelines: sagepub.com/journals-permissions DOI: $10.1|77 /| 9485506|77| 203$ | journals.sagepub.com/home/spp

๑SAGE

\begin{abstract}
Negative stereotyping and stigmatization of welfare recipients may account for the negative outcomes they experience. Much is known about the impact of stigma on welfare take-up, whereas much is hypothesized about the stigma-unemployment association. In two representative Australian samples, we show that individuals previously exposed to unemployment benefits held negative attitudes to welfare recipients only when these reflected those of their community. Temporal patterns in the data suggest this could reflect an internalization of negative community attitudes. These stigmatizing negative attitudes were not associated with prior unemployment but were linked with current employment, future employment, and a return to employment among the previously unemployed. Community attitudes had no direct effect on employment outcomes. Thus, the effects observed may have an indirect path through the internalization of negative community attitudes. These findings underscore the importance of multilevel analyses of social stigma and highlight that welfare stigma may promote recovery from the underlying characteristic.
\end{abstract}

\title{
Keywords
}

stigma, social status, self/identity, prejudice/stereotyping, norms

Negative stereotypes of welfare receipt are widespread, with recipients of government benefits labeled as "lazy and dependent" (Humpage, 2011; McKay, 2014; Schofield \& Butterworth, 2015). In Australia, which has a welfare regime highly targeted toward those in need (Arts \& Gelissen, 2002; Esping-Andersen, 1989; Lam, 2014), the media labels welfare recipients as "dole bludgers" who are unwilling to work (Archer, 2009). When viewed from the perspective of the stereotype content model, welfare recipients appear stereotyped as low in warmth and competence relative to other social groups (Bye, Herrebrøden, Hjetland, Røyset, \& Westby, 2014; Fiske, Cuddy, Glick, \& Xu, 2002). Across domains, such negative attitudes provide the foundation for stigma and prejudicial treatment (Link \& Phelan, 2006; Phelan, Link, \& Dovidio, 2008). The present work seeks to answer the question of whether the presence of these negative attitudes in the community is associated with unemployment.

Stigma is anticipated by those in need of benefits (O'Donnell, Corrigan, \& Gallagher, 2015). It has often been postulated as a personal cost that explains imperfect welfare take-up rates (Baumberg, 2016; Blundell, Fry, \& Walker, 1988; Contini \& Richiardi, 2012; Garthwaite, 2013; Hernanz, Malherbet, \& Pellizzari, 2004; Kayser \& Frick, 2000; Moffitt, 1983; Stuber \&
Schlesinger, 2006). However, little is known about how stigma impacts return to work. One possibility is that, like some other malleable stigmatized characteristics (e.g., obesity; Major, Hunger, Bunyan, \& Miller, 2014; Puhl \& Heuer, 2010; Vartanian \& Smyth, 2013), welfare stigma will demoralize individuals and maintain the stigmatized characteristic. Another possibility is that it motivates individuals to shed the stigmatized characteristic so as to avoid continued shame and punishment associated with poverty (Sen, 1983).

Welfare stigma can occur at many levels. It may happen directly via acts of harm as suggested by the stereotype content model (Cuddy, Fiske, \& Glick, 2007). Stigmatization also

\footnotetext{
'Centre for Mental Health, Melbourne School of Population and Global Health, The University of Melbourne, Melbourne, Victoria, Australia

${ }^{2}$ Melbourne Institute of Applied Economic and Social Research, The University of Melbourne, Melbourne, Victoria, Australia

Corresponding Author:

Timothy P. Schofield, Centre for Mental Health, Melbourne School of Population and Global Health, The University of Melbourne, Melbourne, Victoria 3010, Australia.

Email: timothy.schofield@unimelb.edu.au
} 
occurs indirectly through the navigation of social and bureaucratic structures (Hatzenbuehler \& Link, 2014). Specifically, stigmatization may result from exposure to negative media portrayals of welfare recipients (Archer, 2009; Golding \& Middleton, 1983; Meers, 2014), through how government agencies and service providers interact with their welfare recipient clients (Baumberg, 2016) or even via exposure to negative attitudes within one's neighborhood (Galster, 2012). Individuals may also hold their own personal stigmatizing views of welfare recipients (Baumberg, 2016). This is labeled self-stigma when those with the characteristic are aware of the stereotype, agree with it, and apply it to themselves (Corrigan, Larson, \& Ruesch, 2009). In the present work, we use negative welfare attitudes in communities as a marker of community stigma and negative individual attitudes as markers of self-stigma and negative attitudes.

There is limited evidence of a direct association between residing in a community where the population holds more stigmatizing, negative attitudes toward welfare on unemployment. Cross-national analyses indicate that countries with more negative attitudes toward welfare also have greater levels of long-term unemployment (Contini \& Richiardi, 2012). Previous within-nation analyses, however, have shown no evidence of an association between areas characterized by high levels of benefit receipt and negative attitudes toward welfare recipients (Bailey, Gannon, Kearns, Livingston, \& Leyland, 2013). Our research expands on this work by studying the association between area-level attitude measures and unemployment of individuals.

Community attitudes may instead have an indirect effect on behavior. Political geographers have articulated the mechanisms by which attitudes are transferred from community to individual (Galster, 2012; Johnston et al., 2004). The most relevant of these to the transmission of welfare attitudes are shaping via interpersonal communication, behavioral modeling, and knowledge acquisition (Bailey et al., 2013). However, there has been little evidence that area-level attitudes toward welfare recipients are actually transferred to individuals. One possibility is that community attitudes have a greater tendency to shape the attitudes of those individuals to whom they are relevant. This nuance is consistent with Cooley's notion of the looking glass self (Cooley, 1902; Shrauger \& Schoeneman, 1979; Tice, 1992; Yeung \& Martin, 2003): How individuals are treated while in possession of a characteristic teaches them about what it means to have the characteristic. This proposition is aligned with thinking regarding how self-stigma develops.

Considering the existing welfare stigma literature, the present research asks two core questions across two studies. First, we examine the association between community and individual attitudes. Specifically, we test whether former welfare recipients hold negative attitudes when these are more consistent with most of those in their community than do nonrecipients. Second, we ask whether stigmatizing attitudes, at either the level of the community or the self, are associated with unemployment. Particularly of interest is future unemployment and returning to work among the recently unemployed.

\section{Study I}

Study 1 examined the cross-sectional associations between community attitudes, individual attitudes, and current employment. We tested whether the relationships between these variables differed for those with recent prior exposure to unemployment benefits and those without.

\section{Method}

\section{Respondents}

The first study investigates respondents $(N=3,243)$ in the Australian Survey of Social Attitudes 2009 (Evans, 2009). The data set is available via the Australian Data Archive (https://www.a da.edu.au/). This is a cross-sectional, nationally representative survey of Australians drawn from the electoral role (mandatory for adults, entry available from 17). We considered individuals who were not currently at high school and aged under 65 (the typical age at which Australians are eligible for a government provided Age Pension). Sample size was determined by the number of in-scope cases in the data set. The 2,369 respondents had their welfare attitudes measured and were used for the generation of community attitude scores. The majority had responses on the covariates and were subsequently used in the analyses of at least one of the two modeled outcomes. The group used to model individual attitudes is the largest subset and contained 2,251 respondents (1,290 women).

\section{Measures}

Attitudes. Individuals may hold distinct opinions about each part of the welfare system (Roosma, Gelissen, \& van Oorschot, 2013; Schofield \& Butterworth, 2015). Welfare attitudes may concern structural aspects of the system, specific payments, or the recipients of welfare. Previous analyses of the nine welfare attitude items included in this survey showed their multivariate segmentation into attitudes toward the recipients of welfare, the importance of a welfare system (i.e., "cutting welfare benefits would damage too many people's lives"), and payments unrelated to unemployment (i.e., "all families deserve payments from the government to help with the costs of raising children" and "single parents deserve government payments, so they can be home to raise their children"; Schofield \& Butterworth, 2015). Only the 6 items concerning the recipients of welfare were included in this analysis (e.g., "welfare makes people lazy and dependent" and "people could find a job if they wanted to"). Data from individuals who answered any of the 6 target items were used, with responses missing to $3.4 \%$ of items. All items were coded, such that higher scores indicate a more negative and stigmatizing view of welfare recipients.

Individual attitudes. Each item was standardized. The respondent's negativity toward welfare recipients was then calculated as the mean of the standardized items to which they responded. Standardizing items removes the cross-item variability in mean and variance and enables calculation of a less biased mean when responses to some items are missing. Scale reliability was 
calculated from those who responded to all 6 items and was adequate $(\alpha=.794)$. Principal components analysis suggested a single component with eigenvalue $>1$ which accounted for $50.41 \%$ of the variance. Prior work using an overlapping set of items in an Australian sample found that having negative attitudes toward welfare predicted opinions favoring reducing and enforcing welfare conditionality, while positive attitudes predicted opinions favoring targeting welfare and expanding services (Wilson, Spies-Butcher, \& Stebbing, 2009).

Community attitudes. A measure of negative welfare attitudes in the community was created by taking the sampling-weight weighted mean of all individuals within each respondent's federal electoral division ( 150 divisions, $n_{m}=15.73, n_{S D}=$ 4.94). When weights are not available, the simple mean of respondents within region is typically used (Zhang, Zyphur, \& Preacher, 2009). Weighting accounts for everyone's respective representativeness in the population. The correlation between community and individual attitudes was $r=.18, p<.001$.

Exposure to unemployment benefits. Unemployment benefits are not time limited in Australia, which allows long-term receipt of welfare. Prior exposure to unemployment benefits was defined as the respondent responding affirmatively to an item asking whether they or their partner had received unemployment benefits in the last 5 years. No other items in the data set concerned prior unemployment benefit receipt.

Unemployment. Unemployment was coded based on participants' self-reported work activities in the last week.

Covariates. We identified several sociodemographic covariates that could be controlled in the data set. These were age, gender, household income, whether an individual was partnered, whether they were born in Australia, level of education, and an indicator of not being in the labor force. With the exceptions of household income and level of education, the processing of which is described below, these variables were modeled as coded in the data set (see Table 1).

Household income. The data set contained two income variables, an individual income variable and a household income variable. One of the options for household income was the "same as above," referring to the individual income item. These two responses were merged as appropriate after harmonizing the levels of response available across the two questions. Due to low frequencies in some levels of income, the ordinal categories of household income were then grouped, so that each level contained at least $10 \%$ of nonmissing income data. An indicator of missing income was included.

Education. To generate level of education, we first classified secondary education into high school completers and noncompleters. For those who reported no education since leaving high school, this indicator was used. Everyone else was categorized as having a nonuniversity tertiary qualification, a bachelor degree, or a postgraduate degree.

\section{Analytic Strategy}

Analyses were performed with multilevel mixed-effects models in STATA 14.2 to account for the regional clustering in the data. Two sets of models were considered: multilevel mixedeffect regressions predicting individual attitudes from community attitudes and multilevel mixed-effect logistic regressions predicting unemployment from individual attitudes and community attitudes. Random intercepts were modeled for each community in both model sets. Unadjusted models were first performed for each outcome, covariates were then added to the model, and finally, the interactions of attitudinal predictors with prior exposure to unemployment benefits were added.

\section{Results}

Descriptive statistics for those with and without prior exposure to unemployment benefits are presented in Table 1. Comparisons between these two groups indicated that people with prior exposure to unemployment benefits were represented across most regions $(69 \%)$ and were no more likely to be in a region with negative attitudes about welfare recipients, $t(2249)=$ $1.58, p=.115$. However, those with prior exposure were less likely to hold negative attitudes about welfare recipients, $t(2249)=6.08, p<.001$, and more likely to currently be unemployed, $\chi^{2}(1)=42.61, p<.001$.

The first models predicted individual welfare attitudes. Results of the unadjusted model are presented only in text. Table 2 presents additional results of the adjusted model and the models containing the interaction terms. Negative community attitudes were reliably associated with negative individual attitudes, unadjusted: $b(S E)=0.48(0.06), p<.001$; adjusted: $b$ $(S E)=0.44(0.05), p<.001$, and prior exposure to unemployment benefits was associated with less negative individual attitudes, adjusted: $b(S E)=-0.25(0.05), p<.001$. These two predictors interacted such that those with prior exposure to unemployment benefits held increasingly negative attitudes to the extent their community held negative attitudes, interaction: $b(S E)=0.52(0.20), p=.008$. This interaction is plotted as marginal means at $\pm 1 S D$ of community attitudes in Figure 1. In communities with less negative welfare attitudes, prior recipients of unemployment benefits hold significantly less negative individual attitudes than those with no history of unemployment benefit receipt $(b=-0.37,95 \%$ CI $[-0.51,-0.23], z=5.29$, $p<.001)$, but there was no difference due to prior exposure in communities with more negative welfare attitudes $(b=-0.10$, $95 \%$ CI $[-0.26,0.05], z=1.33, p=.182$ ).

The second models tested the predictors of unemployment. Again, the results of the unadjusted model are presented only in text. Table 2 presents the results of the adjusted and interaction containing models, reporting odds ratios $(O R \mathrm{~s})$. ORs greater than 1 indicate an increased likelihood of unemployment, whereas $O R$ s less than 1 indicate a reduced likelihood of unemployment. Negative community attitudes were not associated with individual unemployment status, unadjusted: $O R(S E)=$ 0.49 (0.27), $p=.189$; adjusted: $O R(S E)=0.38(0.25), p=$ 
Table I. Descriptive Characteristics of Study I Sample on Prior Exposure to Unemployment Benefits in the Last 5 Years.

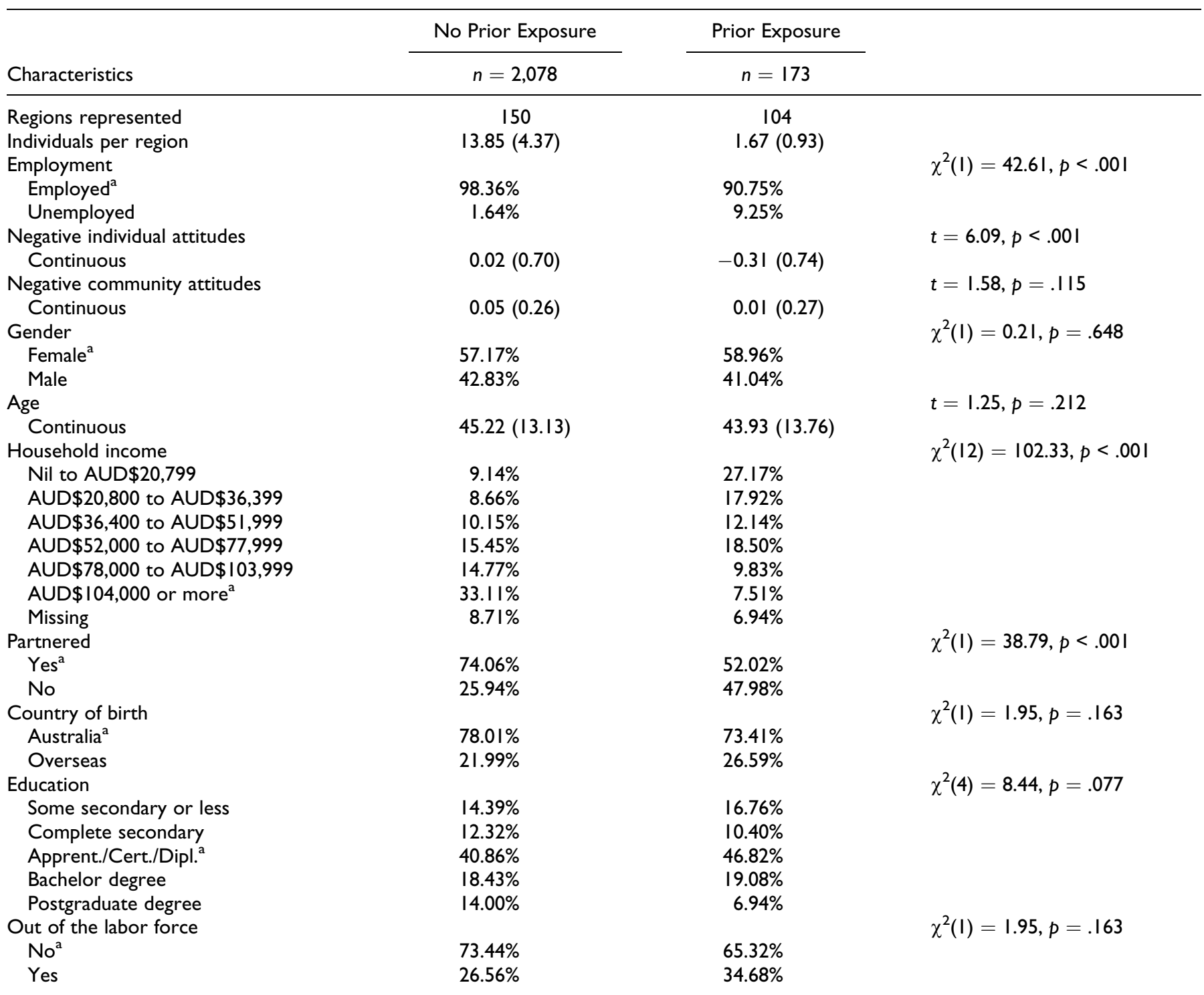

Note. Data are counts, \%, or mean (SD) within level of prior exposure to unemployment benefits.

${ }^{a}$ Reference category, this was determined based on the most common level.

.136 , while negative individual attitudes were associated with a lower likelihood of unemployment in both the unadjusted and adjusted models, unadjusted: $O R(S E)=0.36(0.08), p<$ .001 ; adjusted: $O R(S E)=0.53(0.14), p=.013$. Prior exposure to unemployment benefits was associated with a greater likelihood of unemployment, adjusted: $O R(S E)=3.64$ (1.47), $p=.001$, but did not interact with either community attitudes, interaction: $O R(S E)=1.79(2.51), p=.679$, or individual attitudes, unadjusted: $O R(S E)=0.61(0.39), p=.442$. This remained true if each interaction was fitted separately.

\section{Discussion}

Although a history of exposure to unemployment benefits was associated with possessing less negative attitudes toward welfare recipients, those with recent experiences of unemployment benefits were also more likely to hold negative attitudes if these were present in their communities. These findings extend prior cross-sectional work which showed an association between contemporaneous welfare receipt and attitudes (Bailey et al., 2013), by demonstrating an association between prior welfare receipt and current attitudes. The distinction between timing of welfare receipt and attitudes suggests the results may be consistent with the internalization hypothesis; that community welfare attitudes are internalized by those for whom they are self-relevant. We also found that the more negative an individual's attitudes toward welfare recipients, the less likely they are to be unemployed. This effect of negative individual attitudes complements prior work examining how welfare stigma acts as a deterrent to payment take-up (Baumberg, 2016; Blundell et al., 1988; Contini \& Richiardi, 2012; Garthwaite, 2013; Hernanz et al., 2004; Kayser \& Frick, 2000; Moffitt, 1983; Stuber \& Schlesinger, 2006). 


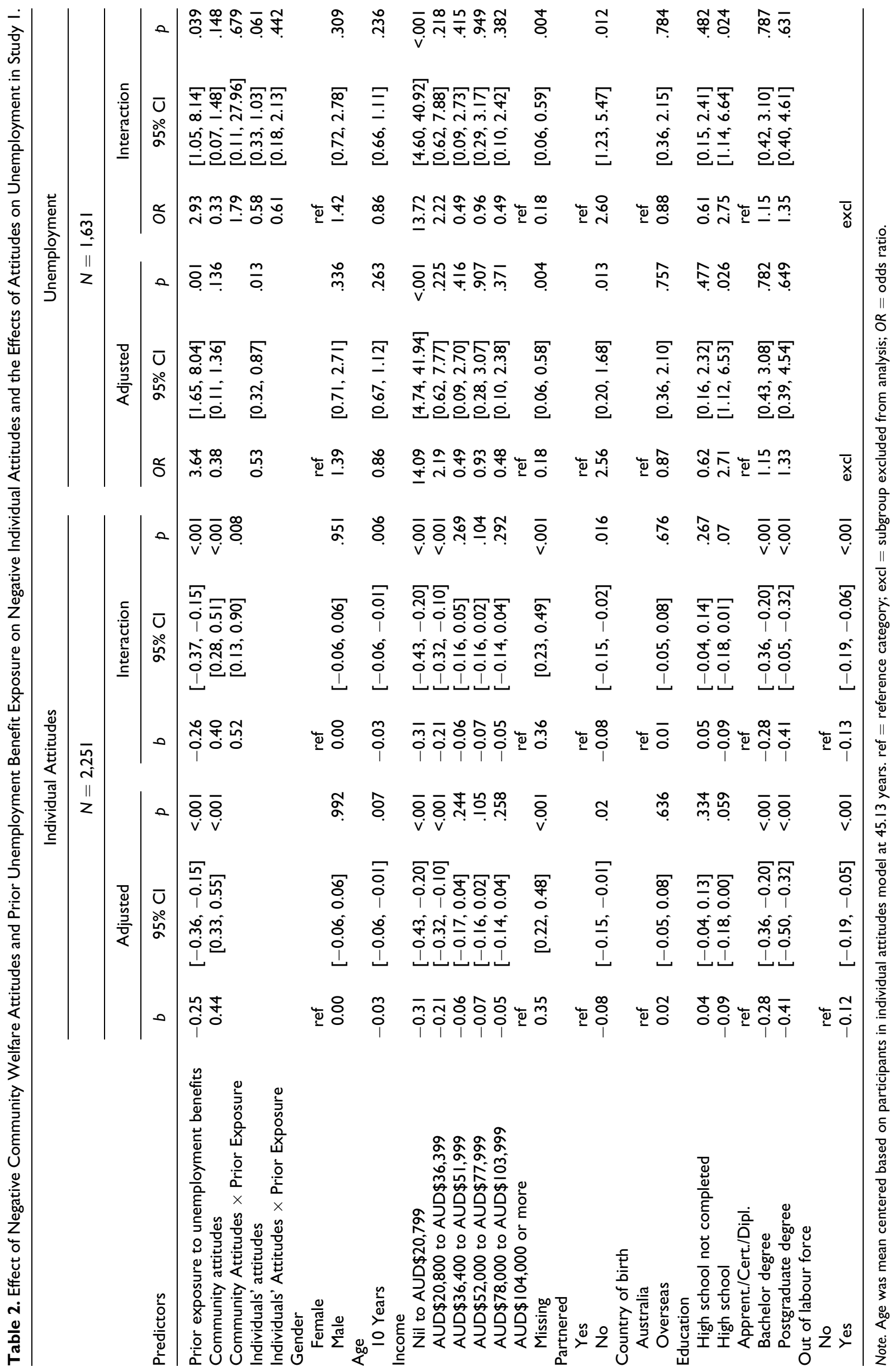




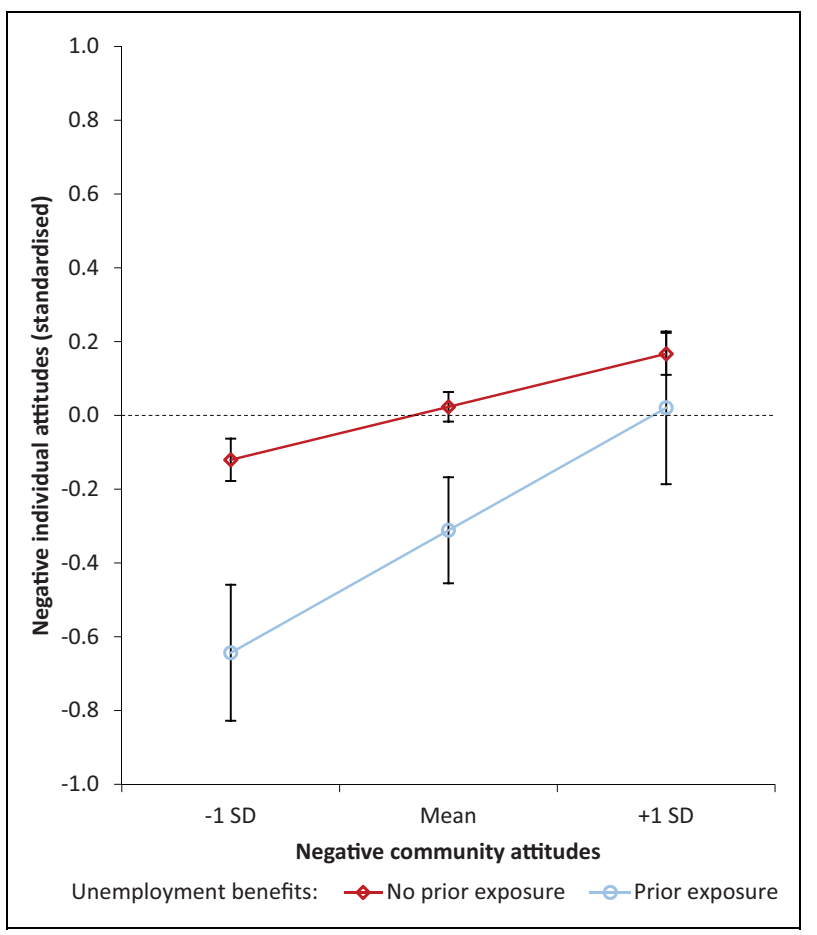

Figure I. Interactive effect of prior exposure to government benefits and negative community attitudes on the negative individual attitudes in Study I. The values of community attitudes are -0.21 at $-I S D$, 0.04 at the mean, and 0.30 at + I SD. The unstandardized mean of individual attitudes is 0.00 with an SD of 0.71 . The $95 \% \mathrm{Cls}$ of marginal means are plotted.

Secondary analyses of existing data are frequently limited by the original items. For instance, our metric of prior unemployment benefit receipt was limited to a single item covering the prior 5 years. There were no further items available to examine the effect over different periods of prior exposure, whether these were effects of prior unemployment or benefit receipt per se, or the contribution of individual relative to familial experience of benefits. The implications of not having true longitudinal information should also be considered. Perhaps rather than community attitudes being linked to internalization of stigmatizing attitudes among welfare recipients, welfare recipients select into communities that share their welfare attitudes through preference or economic necessity. All other variables were measured contemporaneously, which allows some alternate explanations of the results. For instance, given the same strength of relationship between attitudes and employment for welfare recipients and nonrecipients alike, it may be that negative attitudes to welfare are driven by current employment status. This would be expected if welfare attitudes are a self-serving consequence of current circumstances designed to ameliorate cognitive dissonance.

\section{Study 2}

Study 2 draws upon data from a different national study. This study is longitudinal and allowed more precise measurement of prior welfare receipt and different specifications of employment status to be considered. First, we sought to replicate the findings from Study 1 in this new data set. Then, to more appropriately analyze the associations between welfare stigma and behavior, we tested whether welfare attitudes were associated with future unemployment. To directly test the return to work hypothesis, we examined continued unemployment among a subsample of recently unemployed individuals. Finally, to consider the alternate possibility that attitudes are a product of employment, we examined whether attitudes were also associated with prior unemployment.

\section{Method \\ Respondents}

A sample of working age individuals (i.e., 15 to the age of eligibility for the age pension) was drawn from the Household, Income, and Labour Dynamics in Australia (HILDA) Survey Waves 1 (2001) to 6 (2006), a nationally representative household panel survey of Australians. Information on data access is available via the Melbourne Institute (https://www.melbour neinstitute.com/hilda/). Sample size for the various models was determined by the number of in-scope cases in the data set. The 9,285 respondents had their welfare attitudes measured and were used for the generation of community attitudes scores. The majority also had responses on the covariates and were subsequently used in the analyses of at least one of the five modeled outcomes. The group used to model individual attitudes is the largest subset and contained 7,945 respondents (4,051 women).

\section{Measures}

Attitudes. A single-item measure of negativity toward receiving government welfare was available in Wave 5 of the HILDA Survey. Respondents were asked to rate from (1) not at all important to (7) very important whether a benefit from paid employment was "not having to be reliant on the Government for income support." Higher scores indicate a more negative attitude toward welfare receipt. Responses to this item were centered at the midpoint of the scale (i.e., 4) and formed the measure of individual attitudes.

Community attitudes. The measure of negative welfare attitudes in the community was created by taking the sampling-weight weighted mean of all individuals within each respondent's community. In Wave 1, 488 Census Collection Districts $\left(n_{m}=19.14, n_{S D}=7.89\right)$ were used as part of the sampling design. They are available in an anonymized form. Census Collection Districts are compact regions with visible boundaries (main roads, train lines, and rivers) and that were walkable in urban areas. There is no more recent area variable that could have been used for community clustering. Therefore, the Census Collection District provides a proxy for current area and does not account for those who have moved 
since initially sampled. The correlation between community and individual attitudes was $r=.21, p<.001$.

Exposure to unemployment benefits. Prior exposure to unemployment benefits was defined from reporting current personal receipt of unemployment benefits at the prior waves. For replication of the contemporaneous models of Study 1, this was Waves 1-4. Exposure was defined from Waves 1-3 for prediction of prior unemployment and Waves $1-5$ for future unemployment.

Unemployment. Unemployment was coded based on respondents reported employment and labor force status.

Covariates. Several sociodemographic covariates were again controlled. These were largely the same as Study 1, with age, gender, and equivalized household income, whether an individual was partnered, level of education, full-time student status, and an indicator of whether the person was not in the labor force included. Country of birth was not included as it showed no significant effects in Study 1. Variable levels are presented in Table 3. Reference categories were selected based on Study 1 for comparability. Partner status now considered previously partnered individuals separately from never partnered individuals because information on being divorced, separated, or widowed was available. Processing of education and income is described below. Two area-level characteristics, unemployment rate, and socioeconomic circumstances (SES) were also controlled.

Household income. The continuous measure of household income was equivalized for household size and composition using the Organization for Economic Co-operation and Development (OECD)-modified formula (Hagenaars, De Vos, \& Zaidi, 1996). Equivalization is used to reflect the practical benefit of household income. Insufficient detail was available in Study 1 to equivalize household income. Examining those participants described in Table 3 indicated a median value of AUD $\$ 42,550$ (Inter-quartile range [IQR]: AUD $\$ 28,487$ to AUD $\$ 59,142$ ) but a maximum of AUD $\$ 847,008$. As this range created the possibility of undue influence from extreme outliers, we coded equivalized household income into quintiles. Reported results did not change if the continuous measure was used instead.

Education. Examining those participants described in Table 4 indicated insufficient counts of postgraduate degrees in those with prior exposure to unemployment benefits to consider these as a distinct category $(n=9)$. As such, postgraduate degrees were grouped with other university qualifications.

Area-level metrics. The area-level unemployment rate is based on the state or its capital city in October of the interview year. Area SES is based on decile of the Australian Bureau of Statistic's Index of Relative Socio-Economic Advantage and Disadvantage in each Statistical Area Level 1 in 2011 (approximately
400 people). The location of the respondent is not identifiable as just the decile value is provided.

\section{Analytic Strategy}

The multilevel mixed-model regressions predicting individual attitudes from Study 1 were first replicated. Next, we replicated and extend the multilevel mixed-model logistic regressions predicting unemployment. While Study 1 just tested contemporaneous unemployment as an outcome, we also sought to test associations with unemployment in the past and future. We also modeled continued unemployment using the future unemployment outcome in the subset of people unemployed in the previous wave as this best fits the idea of not returning to work. The measures of individual and community attitudes were taken from Wave 5 in all models. The outcome measure (unemployment) and covariates came from Wave 4 for the prior unemployment models, Wave 5 for current unemployment, and Wave 6 for future unemployment including the continued unemployment model. The indicator of prior unemployment benefits came from the waves prior to the outcome measure (i.e., $1-3,1-4$, and $1-5$, respectively).

\section{Results}

Descriptive statistics for survey respondents included in the individual attitudes models are presented in Table 3. People with prior exposure to welfare were represented across most regions $(57 \%)$ and were no more likely to be in a region with negative attitudes about welfare recipients, $t(7943)=0.01$, $p=.991$. On the other hand, those with prior exposure to unemployment benefits were marginally less likely to hold negative attitudes about welfare recipients, $t(7943)=1.80, p=.071$, and significantly more likely to currently be unemployed than those who had no recent prior exposure to unemployment benefits, $\chi^{2}(1)=313.93, p<.001$.

The first models tested the predictors of individuals' current negative welfare attitudes. Results of the unadjusted model are reported in text. Table 4 additionally presents the results of the adjusted and interaction containing models. Negative community attitudes were reliably associated with negative individual attitudes, unadjusted: $b(S E)=0.76(0.04), p<.001$; adjusted: $b$ $(S E)=0.74(0.04), p<.001$. Prior exposure to unemployment benefits was only marginally associated with more positive individual attitudes, adjusted: $b(S E)=-0.12(0.07), p=$ .066 , but moderated the effect of negative community attitudes. Those with prior exposure to unemployment benefits held increasingly negative individual attitudes to the extent their community held negative attitudes, interaction: $b(S E)=0.45$ $(0.16), p=.004$. This interaction is plotted as marginal means at $\pm 1 S D$ of community attitudes in Figure 2 . In communities with less negative welfare attitudes, prior recipients of unemployment benefits hold significantly less negative individual attitudes than those with no history of unemployment benefit receipt, $b=-0.29,95 \%$ CI $[-0.47,-0.12], z=3.28, p=$ 
Table 3. Descriptive Characteristics of Study I Sample at Wave 5 Divided on Prior Exposure to Unemployment Benefits in Waves I-4.

\begin{tabular}{|c|c|c|c|}
\hline & No Prior Exposure & Prior Exposure & \\
\hline Individuals per region & $|5.3|(6.88)$ & $1.87(1.13)$ & \\
\hline Employment & & & $\chi^{2}(I)=313.93, p<.001$ \\
\hline Employed $^{\mathrm{a}}$ & $97.30 \%$ & $79.40 \%$ & \\
\hline Continuous & $\mathrm{I} .78(\mathrm{I} .44)$ & $1.66(1.54)$ & \\
\hline Negative community attitudes & & & $t=0.01, p=.991$ \\
\hline Continuous & $\mathrm{I} .75(0.37)$ & $\mathrm{I} .75(0.4 \mathrm{I})$ & \\
\hline Gender & & & $\chi^{2}(1)=16.39, p<.001$ \\
\hline Female $^{\mathrm{a}}$ & $51.59 \%$ & $42.42 \%$ & \\
\hline Male & $48.41 \%$ & $57.58 \%$ & \\
\hline Second quintile & $19.92 \%$ & $21.11 \%$ & \\
\hline Third quintile & $20.73 \%$ & $9.60 \%$ & \\
\hline Fourth quintile & $20.95 \%$ & $6.33 \%$ & \\
\hline Fifth quintile ${ }^{a}$ & $21.17 \%$ & $3.26 \%$ & \\
\hline Average (AUD $\$ 10,000)$ & $5.02(3.70)$ & $2.63(1.76)$ & $K-S D=0.46, p<.001$ \\
\hline Partnered & & & $\chi^{2}(2)=123.32, p<.001$ \\
\hline Previously & $8.24 \%$ & $20.15 \%$ & \\
\hline Never & $24.39 \%$ & $33.21 \%$ & \\
\hline$Y_{e s}{ }^{a}$ & $67.36 \%$ & $46.64 \%$ & \\
\hline Full-time student & & & $\chi^{2}(I)=5.33, p=.021$ \\
\hline $\mathrm{No}^{\mathrm{a}}$ & $90.42 \%$ & $93.47 \%$ & \\
\hline Yes & $9.58 \%$ & $6.53 \%$ & \\
\hline Continuous & $4.85(1.13)$ & $4.94(1.14)$ & \\
\hline Out of labour force & & & $\chi^{2}(I)=70.05, p<.001$ \\
\hline $\mathrm{No}^{\mathrm{a}}$ & $84.78 \%$ & $70.83 \%$ & \\
\hline Yes & $15.22 \%$ & $29.17 \%$ & \\
\hline
\end{tabular}

Note. Data are $n$, \%, or mean (SD) within level of prior exposure to unemployment benefit. Kolmogorov-Smirnov (K-S) test is used where there is no equality of variance. This is the sample used to predict individual attitudes.

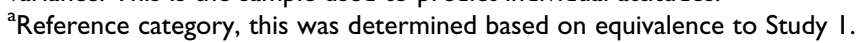

.001 ; there was no difference due to prior exposure to unemployment benefits in communities with more negative welfare attitudes, $b=0.05,95 \% \mathrm{CI}[-0.13,0.22], z=0.54, p=.591$.

The second models tested the predictors of unemployment. Results of the unadjusted and interaction models are reported only in text. Table 5 additionally presents the results of the adjusted models. Irrespective of timing of unemployment, negative community attitudes were not associated with unemployment in the unadjusted models, prior: $O R(S E)=0.99(0.17)$, $p=.953$; current: $O R(S E)=0.95(0.17), p=.795$; future: OR $(S E)=1.01(0.19), p=.958$; continued unemployment: $O R(S E)=1.25(0.54), p=.610$, whereas negative individual attitudes were significantly, prior: $O R(S E)=0.89(0.03)$, $p=.003$; current: $O R(S E)=0.90$ (0.04), $p=.009$; future: $O R(S E)=0.89(0.04), p=.006$, or marginally associated with unemployment in the unadjusted models, continued unemployment: $O R(S E)=0.81(0.09), p=.060$. After adjustment, however, negative individual attitudes ceased being associated with prior unemployment, $O R(S E)=0.98(0.05), p=.769$, but continued to be associated with lower current unemployment and future unemployment, even when the sample was restricted to the recently unemployed, current: $O R(S E)=0.90(0.04)$, $p=.022$; future: $O R(S E)=0.90(0.04), p=.032$; continued unemployment: $O R(S E)=0.75(0.11), p=.049$. Prior 
Table 4. Effect of Negative Community Welfare Attitudes and Unemployment Benefit Exposure in Waves I-4 on Negative Individual Attitudes Obtained via Linear Mixed-Model Regressions in Study 2.

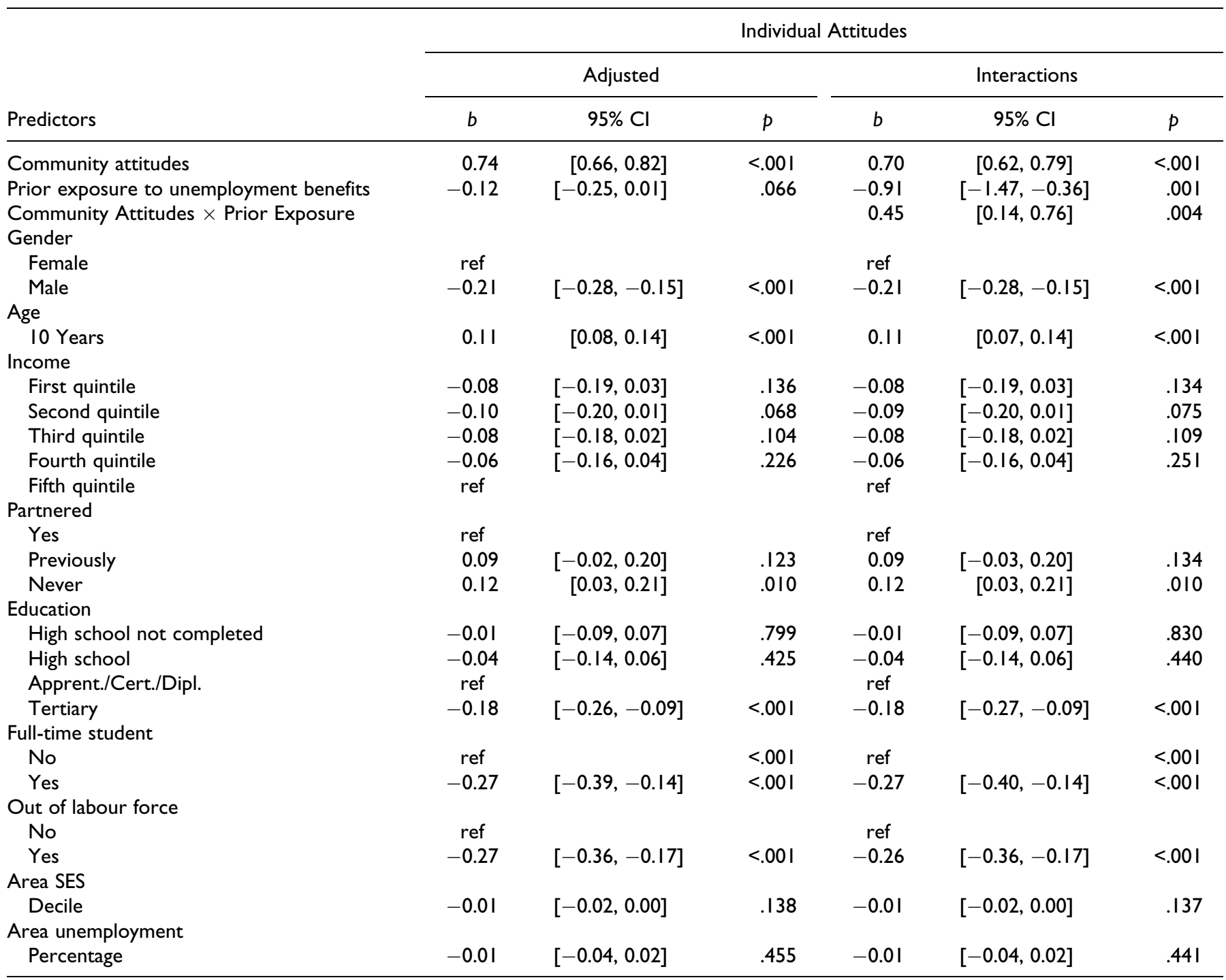

Note. $n=7,945$. Age was mean centered at 38.98 years. Reference categories are consistent with Study I where applicable.

exposure to unemployment benefits was associated with a greater likelihood of unemployment $(O R \mathrm{~s}>5.05, p \mathrm{~s}<.001)$ except when modeling continued unemployment, $O R(S E)=$ $1.89(0.85), p=.157$. There were no interactions between prior exposure to unemployment benefits and either of the attitudinal measures for any of the four outcomes ( $p s \geq .197)$.

\section{Discussion}

We found that those with recent prior exposure to unemployment benefits possessed more favorable individual attitudes toward welfare, except when their communities had negative welfare attitudes. In these communities, those who used to receive unemployment benefits had attitudes consistent with everyone else. This finding replicated Study 1. Moreover, individual but not community attitudes were again associated with current unemployment. This replication occurred despite a briefer measure of negative welfare attitudes and a marker of individual rather than familial prior exposure to unemployment benefits. The extension involving the analyses of unemployment at different points in time did not provide evidence that unemployment is associated with future welfare attitudes; after accounting for covariates, individual attitudes were not associated with prior unemployment, they were only associated with current and future unemployment. The association of attitudes with future unemployment persisted in the subset of individuals unemployed one wave prior; as such, we conclude that negative welfare attitudes are associated with a lower likelihood of continued unemployment and thus a greater likelihood of return to work. Prior exposure to unemployment benefits was also associated with unemployment in all models except that examining continuing unemployment. Its nonsignificant 


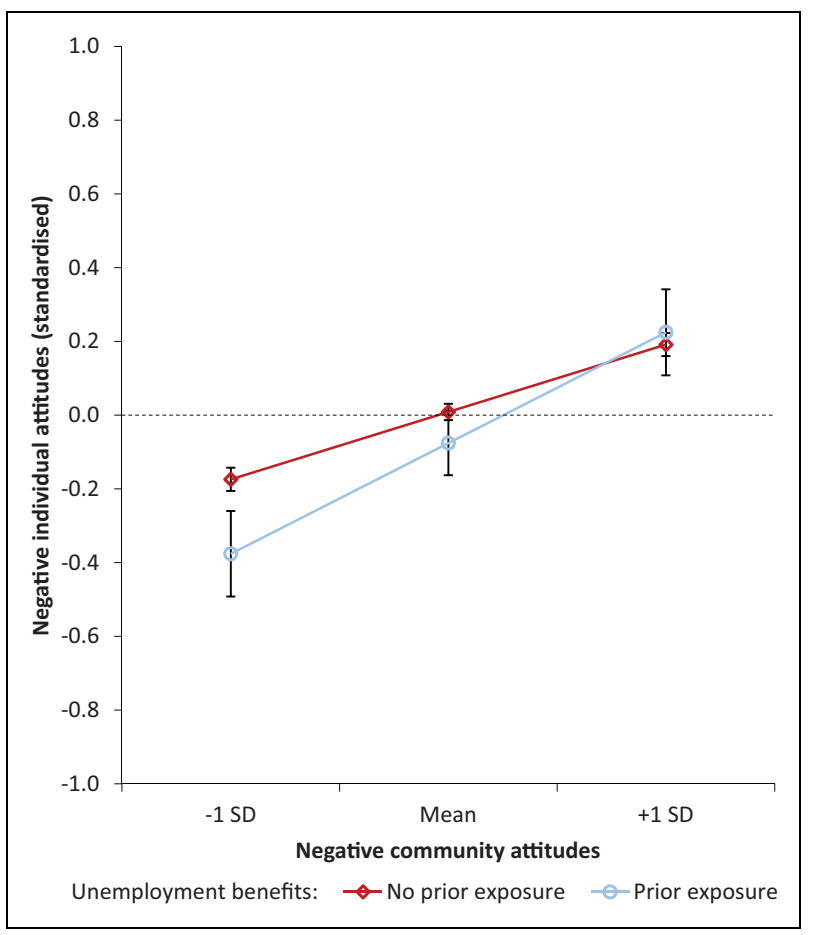

Figure 2. Interactive effect of prior exposure to government benefits and negative community attitudes on the negative individual attitudes in Study 2. The values of community attitudes are I.37 at - I SD, I.75 at the mean, and 2.I2 at +I SD. The unstandardized mean of individual attitudes is I.77 with an SD of I.45. The $95 \%$ Cls of marginal means are plotted.

association with continuing unemployment may reflect its shift from a low-prevalence, highly identifying indicator (4.7-5.5\%) to a common one $(29.1 \%)$ in these analyses.

\section{General Discussion}

This pair of studies advances knowledge of the relationship between stigmatizing welfare attitudes and individual engagement with employment. Recipients of unemployment benefits normally possess sympathetic welfare attitudes (Baumberg, Bell, \& Gaffney, 2012; Schofield \& Butterworth, 2015). Indeed, in both studies, we found evidence that prior recipients of unemployment benefits also have less negative welfare attitudes, but this difference was conditional. Prior recipients of unemployment benefits in communities where people held more negative welfare attitudes did not hold less negative attitudes, but instead were comparable to everyone else in the community. This may reflect a process of internalizing negative community attitudes during the periods of welfare receipt. Moreover, in both studies, we demonstrated that negative individual attitudes toward welfare recipients, but not community ones, were associated with a greater likelihood of current employment. Given the associations between community attitudes and individual attitudes, this may reflect the fact that communities have indirect effects by shaping their members' attitudes rather than direct effects on behavior. Using multiple waves of a longitudinal study, Study 2 then showed that negative individual attitudes were associated with an increased likelihood of employment in the present and future, but not the past. Finally, it was demonstrated that these effects held in the case of those who were recently unemployed returning to work. This pattern of results suggests that negative welfare attitudes may precede employment; however, experimental research would be required to test whether this relationship is causal and unidirectional.

The association between negative welfare attitudes and employment appears robust. One difficulty in contextualizing these findings is that welfare stigma has been blamed for the declines in mental health and psychological well-being observed over spells of unemployment (Butterworth, 2003; Coiro, 2001; Dooley \& Prause, 2002; Ford et al., 2010; Jayakody, Danziger, \& Pollack, 2000; Juon et al., 2010; Kiely \& Butterworth, 2013). The apparent positive impact of stigma observed here on employment may be offset by adverse psychological impact. While the present results do not contradict this prior work, it does suggest that further consideration of a range of outcomes is necessary. Consideration of both welfare stigma's costs (e.g., to mental health) and benefits (e.g., lower likelihood of unemployment) may reveal distinct effects of being stigmatized by others and self-stigma (see Baumberg, 2016). It could also reveal the presence of two distinct outcomes among people: One set of individuals may experience the mental health decline, while another set promptly finds employment. If this is the case, it is important to determine the moderating factors responsible for determining which of these outcomes are more likely. The view that stigma can be used as a tool to drive economically desirable behavioral outcomes is routinely observed as a basis for governmental policy (Baumberg et al., 2012), has been suggested in the literature on benefit take-up rates (Kayser \& Frick, 2000; Moffitt, 1983), and formally conceptualized of as stigma power (Link \& Phelan, 2014). The current findings should not be taken as support for strategies advocating stigmatization of welfare recipients to promote employment until the comprehensive effects of welfare stigma are better understood.

One strength of the current evidence that stigma may be associated with recovery from unemployment is that it comes from large, nationally representative data sets. However, although the studied samples were large for psychological research, the number of former welfare recipients and unemployed individuals were more modest. As the two studies used negative attitudes as markers of welfare stigma rather than measures of experienced discrimination due to welfare receipt, there is scope for future work to be guided by the discrimination literature (Baumberg, 2016; Major \& O’Brien, 2005). Still, the use of attitudinal items as a proxy is consistent with typical conceptualizations of negative attitudes and stereotypes underscoring prejudicial behavior (Link \& Phelan, 2006; Phelan et al., 2008). Future work may consider whether exposure to welfare-based discrimination predicts similar outcomes to those observed for negative attitudes.

The present research makes two novel contributions to the literature. First, we demonstrate that individuals with a history 


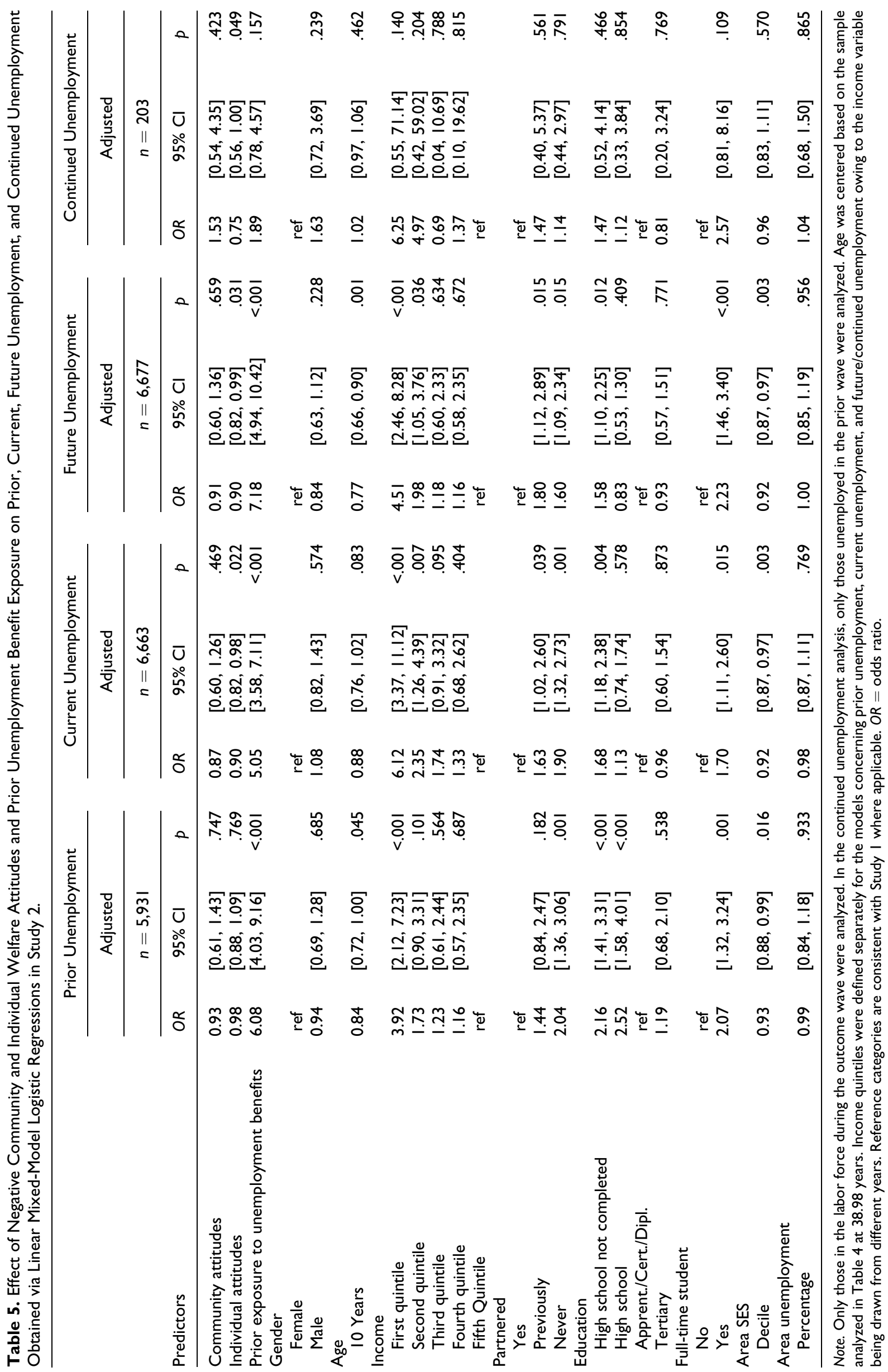


of welfare receipt are more likely to hold negative views toward welfare recipients if this is consistent with others in their community. This suggests that stigmatizing community attitudes is perhaps more likely to be internalized by individuals to whom they are most directly applicable. Second, holding negative welfare attitudes is associated with current employment, future employment, and returning to work if recently unemployed. These results suggest that stigma can, in some cases, be linked to the shedding of a stigmatized characteristic. Importantly, these findings should not be considered a tool for policy action until causality is clearly demonstrated, and the economic benefits of a larger labor force are weighed up against the burden of mental health problems and other associated social costs.

\section{Declaration of Conflicting Interests}

The author(s) declared no potential conflicts of interest with respect to the research, authorship, and/or publication of this article.

\section{Funding}

The author(s) disclosed receipt of the following financial support for the research, authorship, and/or publication of this article: This project was supported by Australian Research Council (ARC) Project Grants awarded to Peter Butterworth (DP120101887; DP160104178). Peter Butterworth was supported by a Future Fellowship from the ARC (FT13101444). The funder played no role in conceptualization, design, implementation, interpretation or approval of the study.

\section{References}

Archer, V. (2009). Dole bludgers, tax payers and the New Right: Constructing discourses of welfare in 1970s Australia. Labour History, 96, 177-190.

Arts, W., \& Gelissen, J. (2002). Three worlds of welfare capitalism or more? A state-of-the-art report. Journal of European Social Policy, 12, 137-158.

Bailey, N., Gannon, M., Kearns, A., Livingston, M., \& Leyland, A. H. (2013). Living apart, losing sympathy? How neighbourhood context affects attitudes to redistribution and to welfare recipients. Environment and Planning A, 45, 2154-2175.

Baumberg, B. (2016). The stigma of claiming benefits: A quantitative study. Journal of Social Policy, 45, 181-199.

Baumberg, B., Bell, K., \& Gaffney, D. (2012). Benefits stigma in Britain. London, England: Turn2Us.

Blundell, R., Fry, V., \& Walker, I. (1988). Modelling the take-up of means-tested benefits: The case of housing benefits in the United Kingdom. The Economic Journal, 98, 58-74.

Butterworth, P. (2003). The prevalence of mental disorders among income support recipients: An important issue for welfare reform. Australian and New Zealand Journal of Public Health, 27, 441-448.

Bye, H. H., Herrebrøden, H., Hjetland, G. J., Røyset, G. Ø., \& Westby, L. L. (2014). Stereotypes of Norwegian social groups. Scandinavian Journal of Psychology, 55, 469-476.

Coiro, M. J. (2001). Depressive symptoms among women receiving welfare. Women \& Health, 32, 1-23.
Contini, D., \& Richiardi, M. G. (2012). Reconsidering the effect of welfare stigma on unemployment. Journal of Economic Behavior \& Organization, 84, 229-244.

Cooley, C. H. (1902). Human nature and the social order (Seventh Printing, 2009). New Brunswick, NJ: Transaction Publishers.

Corrigan, P. W., Larson, J. E., \& Ruesch, N. (2009). Self-stigma and the "why try" effect: Impact on life goals and evidence-based practices. World Psychiatry, 8, 75-81.

Cuddy, A. J., Fiske, S. T., \& Glick, P. (2007). The BIAS map: Behaviors from intergroup affect and stereotypes. Journal of Personality and Social Psychology, 92, 631.

Dooley, D., \& Prause, J. (2002). Mental health and welfare transitions: Depression and alcohol abuse in AFDC women. American Journal of Community Psychology, 30, 787-813.

Esping-Andersen, G. (1989). The three worlds of welfare capitalism. Chichester, England: John Wiley.

Evans, A. (2009). The Australian Survey of Social Attitudes, 2009 [Computer File]. Canberra: Australian Data Archive, The Australian National University.

Fiske, S. T., Cuddy, A. J., Glick, P., \& Xu, J. (2002). A model of (often mixed) stereotype content: Competence and warmth respectively follow from perceived status and competition. Journal of Personality and Social Psychology, 82, 878.

Ford, E., Clark, C., McManus, S., Harris, J., Jenkins, R., Bebbington, P., ... Stansfeld, S. (2010). Common mental disorders, unemployment and welfare benefits in England. Public Health, 124, 675-681.

Galster, G. C. (2012). The mechanism(s) of neighbourhood effects: Theory, evidence, and policy implications. In M. van Ham, D. Manley, L. Simpson, N. Bailey, \& D. Maclennan (Eds.), Neighbourhood effects research: New perspectives (pp. 23-56). Dordrecht, the Netherlands: Springer.

Garthwaite, K. (2013). Fear of the brown envelope: Exploring welfare reform with long-term sickness benefits recipients. Social Policy \& Administration. doi:10.1111/spol.12049

Golding, P., \& Middleton, S. (1983). Images of welfare: Press and public attitudes to poverty. Oxford, England: Blackwell.

Hagenaars, A. J., De Vos, K., \& Zaidi, M. A. (1996). Poverty statistics in the late 1980s: Research based on micro-data. Luxembourg: Office for Official Publications of the European Communities.

Hatzenbuehler, M. L., \& Link, B. G. (2014). Introduction to the special issue on structural stigma and health. Social Science \& Medicine, 103, 1-6.

Hernanz, V., Malherbet, F., \& Pellizzari, M. (2004). Take-up of welfare benefits in OECD countries: A review of the evidence, OECD social, employment and migration Working Papers, No. 17. Paris: OECD Publishing. doi:10.1787/525815265414

Humpage, L. (2011). What do New Zealanders think about welfare? Policy Quarterly, 7, 8-13.

Jayakody, R., Danziger, S., \& Pollack, H. (2000). Welfare reform, substance use, and mental health. Journal of Health Politics, Policy and Law, 25, 623-652.

Johnston, R., Jones, K., Sarker, R., Propper, C., Burgess, S., \& Bolster, A. (2004). Party support and the neighbourhood effect: Spatial polarisation of the British electorate, 1991-2001. Political Geography, 23, 367-402. 
Juon, H.-S., Green, K. M., Fothergill, K. E., Kasper, J. D., Thorpe, R. J., \& Ensminger, M. E. (2010). Welfare receipt trajectories of African-American women followed for 30 years. Journal of Urban Health, 87, 76-94.

Kayser, H. A., \& Frick, J. R. (2000). Take it or leave it: (Non-) take-up behavior of social assistance in Germany. Discussion Papers of DIW Berlin 210, DIW Berlin, German Institute for Economic Research. Retrieved from https://ideas.repec.org/p/diw/diwwpp/ dp210.html.

Kiely, K. M., \& Butterworth, P. (2013). Social disadvantage and individual vulnerability: A longitudinal investigation of welfare receipt and mental health in Australia. Australian and New Zealand Journal of Psychiatry, 47, 654-666.

Lam, M. (2014). Living on the disability support pension: 10 case studies and analysis published by the National Welfare Rights Network. Retrieved from http://www.welfarerights.org.au/sites/ default/files/field_shared_attachments/policy/Living\%20 on \%20the\%20Disability\%20Support\%20Pension.pdf

Link, B. G., \& Phelan, J. C. (2006). Stigma and its public health implications. The Lancet, 367, 528-529.

Link, B. G., \& Phelan, J. (2014). Stigma power. Social Science \& Medicine, 103, 24-32.

Major, B., Hunger, J. M., Bunyan, D. P., \& Miller, C. T. (2014). The ironic effects of weight stigma. Journal of Experimental Social Psychology, 51, 74-80.

Major, B., \& O’Brien, L. T. (2005). The social psychology of stigma. Annual Review of Psychology, 56, 393-421.

McKay, S. (2014). Benefits, poverty and social justice. Journal of Poverty and Social Justice, 22, 3-10.

Meers, D. (2014, December 22). Federal cabinet reshuffle: Scott Morrison picks up Social Services portfolio in bid to stop the bludgers. The Daily Telegraph. Retrieved from http://www.dailytelegraph. com.au/news/nsw/federal-cabinet-reshuffle-scott-morrison-picksup-social-services-portfolio-in-bid-to-stop-the-bludgers/storyfni0cx12-1227163795658

Moffitt, R. (1983). An economic model of welfare stigma. The American Economic Review, 75, 1023-1035.

O'Donnell, A. T., Corrigan, F., \& Gallagher, S. (2015). The impact of anticipated stigma on psychological and physical health problems in the unemployed group. Frontiers in Psychology, 6, 1263.

Phelan, J. C., Link, B. G., \& Dovidio, J. F. (2008). Stigma and prejudice: One animal or two? Social Science \& Medicine, 67, $358-367$.
Puhl, R. M., \& Heuer, C. A. (2010). Obesity stigma: Important considerations for public health. American Journal of Public Health, $100,1019$.

Roosma, F., Gelissen, J., \& van Oorschot, W. (2013). The multidimensionality of welfare state attitudes: A European cross-national study. Social Indicators Research, 113, 235-255.

Schofield, T. P., \& Butterworth, P. (2015). Patterns of welfare attitudes in the Australian population. PLoS One, 10, e0142792. doi: 10.1371/journal.pone.0142792

Sen, A. (1983). Poor, relatively speaking. Oxford Economic Papers, 35, 153-169.

Shrauger, J. S., \& Schoeneman, T. J. (1979). Symbolic interactionist view of self-concept: Through the looking glass darkly. Psychological Bulletin, 86, 549.

Stuber, J., \& Schlesinger, M. (2006). Sources of stigma for means-tested government programs. Social Science \& Medicine, 63, 933-945.

Tice, D. M. (1992). Self-concept change and self-presentation: The looking glass self is also a magnifying glass. Journal of Personality and Social Psychology, 63, 435.

Vartanian, L. R., \& Smyth, J. M. (2013). Primum non nocere: Obesity stigma and public health. Journal of Bioethical Inquiry, 10, 49-57.

Wilson, S., Spies-Butcher, B., \& Stebbing, A. (2009). Targets and Taxes: Explaining the welfare orientations of the Australian public. Social Policy \& Administration, 43, 508-525. doi:10.1111/j.14679515.2009.00676.x

Yeung, K.-T., \& Martin, J. L. (2003). The looking glass self: An empirical test and elaboration. Social Forces, 81, 843-879.

Zhang, Z., Zyphur, M. J., \& Preacher, K. J. (2009). Testing multilevel mediation using hierarchical linear models problems and solutions. Organizational Research Methods, 12, 695-719.

\section{Author Biographies}

Timothy Schofield is a research fellow in mental health and social issues. His research is currently focused on the experiences of members of socially stigmatized groups and how these people are perceived by out-group members.

Peter Butterworth is a Professorial Fellow and ARC Future Fellow. His research interests are in the social and economic antecedents and consequences of common mental disorders (anxiety, depression and substance use), with a focus on factors such as work, retirement and deprivation.

Handling Editor: Wiebke Bleidorn 